alcoholic gastritis. $\mathrm{He}$ boasted of a prodigious capacity for alcohol, having drunk 32 litres of beer in one day while in the Congo. He denied having had melaena, but he said rectal bleeding had occurred following a biopsy for anal schistosomiasis. One further symptom he offered was frequent epistaxis.

Our suspicions were aroused because of the circumstances surrounding his arrival at hospital, and because the previous reports were vaguely recalled. However, his claim to be a Rhodesian is probably true, as one of us had attended the school in Bulawayo at which the patient said he had been a pupil, and he correctly named certain teachers.

$\mathrm{He}$ did produce urine containing red cells, and for his pain he was given Diconal (dipipanone and cyclizine). Ninety minutes later he was demanding a stronger analgesic, but he fell asleep before the house-physician could see him. The following day he apparently passed blood into his pyjamas and bed-sheets. Later he called us to see blood coming from the external meatus and trickling on to his thigh, where the blood had clotted. He refused to co-operate with a male nurse in providing a mid-stream specimen of urine.

As he continued to complain of severe pain, and, as we hoped to detain him until a psychiatric opinion could be obtained, he was given chlorpromazine and phenobarbitone sodium. Presumably he realized we were suspicious when neither cystoscopy nor pethidine were forthcoming (perhaps he considers the Aberdonian's reputation for meanness justified!), for he took his discharge approximately 36 hours after admission.

The psychiatrist arrived just in time to glimpse the patient departing along the hospital drive. Needless to say he gave different names in Birmingham, Liverpool, and Aberdeen. Ii seems likely he traumatizes his anterior urethra to produce his haematuria. What we would like to know is his whereabouts and activities between Liverpool and Aberdeen. On admission he claimed to be travelling northwards, and this is perhaps one claim which should be taken seriously.

We wish to thank Dr. C. D. Needham for permission to publish details of this case.

-We are, etc.,

A. C. Young.

G. G. Milie.

L. S. Cantlay.

Woodend General Hospital

Aberdeen.

\section{Bacterial Contamination of Disinfectant}

SIR,-The paper reporting the bacterial contamination of a phenolic disinfectant (14 June, p. 668) was of interest to us. Printol is the commonest disinfectant used in this hospital. The $1 / 100$ working dilution is prepared in the pharmacy and is issued from there in plastic containers. No sterilizing procedure is followed; only a thorough rinse is employed.

During " in use" tests on the lines suggested by Kelsey ${ }^{1}$ carried out on disinfectants in our hospital service we found accidentally that a Gram-negative bacterium could be isolated with ease from any of the $1 / 100$ Printol solutions, whether of long-standing or recent preparation. Specimens of Printol used in the operating-theatre for keeping scrubbing-up brushes and Cheatle forceps also yielded the same organism. Mains tapwater used for diluting the Printol did not contain this bacterium, but it could be isolated from the caps of the plastic containers undiluted Printol was sterile.

The bacterium isolated was a Gram-negative non-motile rod, oxidase positive, which grew feebly at $42^{\circ} \mathrm{C}$., well at $37^{\circ} \mathrm{C}$., but not at all at $50^{\circ} \mathrm{C}$. The organism grew on MacConkey agar, and the citrate utilization test was positive. There was no fermentation of any carbohydrate ; it was indole negative, urease negative, and failed to grow on tetrazolium chloride agar. It gave an alkaline reaction in the Hugh and Leifson test and negative reactions with arginine dihydrolase and gluconate oxidation. It also grew on $0.03 \%$ cetrimide agar but did not show fluorescence. There was no detectable pigment. The organism was resistant to chloramphenicol, penicillin, ampicillin, streptomycin, tetracycline, and the sulphonamides. The organism was difficult to type and for this reason was forwarded to the Central Public Health Laboratory at Colindale, which kindly performed some of the above-mentioned tests, and suggested that it may be an oblique member of the pseudomonad group. It was then sent to the National Collection of Type Cultures for further identification.

Bacteria with the above properties have been recovered from postoperative infections in this hospital, and similar organisms have also been isolated in small numbers from $1 / 5,000$ dilution chlorhexidine used in an irrigation tower.-We are, etc.,

$$
\begin{aligned}
& \text { JoHN CRAGG. } \\
& \text { AlbERT V. ANDREW } \\
& \text { Pathological Laboratory, } \\
& \text { General Hospital, } \\
& \text { Jersey, Channel Islands. } \\
& \text { Reference } \\
& \text { Kelsey, J. C., fournal of Medical Laboratory } \\
& \text { Technology, 1969, 26, 79. }
\end{aligned}
$$

\section{Cervical Spondylosis}

SIR,-Your leading article (14 June, $p$. $650)$ points out that twins are more likely to have some degree of spondylosis than random subjects matched for age, and this is taken io support a hypothesis of genetic aetiology. Similarly, there appears to be a higher incidence of spondylosis in the sibs of one family.

The genetic interpretation is not the only one. In a postural study of secondary modern schoolchildren ${ }^{1}$ I published pictures of pairs of twins who had identical postural and tension defects in the neck and shoulders. I have pointed out elsewhere ${ }^{2}$ that members of the same family, either by mimicry or direct instruction, tend to fall into the same postural and tension habits. Unfortunately, these are usually overlooked, both clinically and radiologically, in the consideration of patients with cervical spondylosis. Likewise, in the treatment of patients with cervical spondylosis, there is too little awareness of the complex and distorted patterns of mus cular hypertension which are manifested in the neck, and which can reasonably be held to be responsible for some of the root symptoms as well as for the variation in such symptoms in patients with the same degree of spondylosis. I myself would go further and postulate that such distorted tension habits have a causative role, and that lack of recognition of these factors is responsible for the often unsatisfactory results of treatment. -I am, etc.

London, S.W.7.

WiLfREd BARLOW.

References

1 Barlow, W., in Proceedings of the Fourth International Congress of Physical Medicine. Amsterdam, Excerpta Medica, 1966.

2 Barlow, W., British fournal of Clinical Practice, 1959, 13, 339 .

\section{Death Wishes}

SIR,-I should like to suggest that all potential donors carry with them a card bearing details of their health, and indicating their wishes regarding organ transplantation in the event that they meet with sudden violent death away from home.

I have designed such a card which carries on one side the full name, address, and telephone number of the bearer, and a signed declaration by him reading as follows: "In the event of irreversible and incurable damage to the brain of the bearer that will cause permanent cessation of consciousness and imminent death, organs and tissues may be used for transplantation at the discretion of the first pair of hospital doctors to see this card." On the reverse side of the card is space to fill in what disease, if any, the bearer has, the name of the doctor and the hospital under whose care he is, and the drugs, including dose, which he is presently taking. The religion, the name of someone who should be contacted in case of accident, and the bearer's preference for disposal of his body-for example, burial, cremation, or anatomical study-is also included.

Use of these cards may well facilitate the rapid transfer of donor tissues, reducing to the minimum interviews with distressed relatives conducted in undignified haste. I have produced a limited number of these cards and would be happy to send them to anyone sending a stamped and addressed envelope. If there is sufficient demand and approval by workers in the field, I shall approach the Department of Health and suggest that they take over the production of these cards on a large scale. I should be most grateful for suggestions, additions, modifications, etc. -I am, etc.,

\section{Lansdowne Road, \\ London $\mathbb{W} .11$.}

T. FAULKNER.

\section{Education of Doctors' Orphans}

SIR,-As the end of Medical Charities Year approaches it may interest some of your readers to know of the existence of the Philip Matthews Memorial Scholarship created to assist the sons of deceased or disabled doctors who have practised medicine in East Sussex.

The funds are held by a well-known school's appeal foundation, and the headmaster has recently most generously indicated his willingness to make moneys available where necessary to any other school. $\mathrm{He}$ is advised by a consultant, a public health medical officer, and a general practitioner. All expenses in connexion with the scholarship are privately borne.

Two boys are at present receiving substantial bursaries and a third case is in the pipeline. The fathers of all these boys died in 